\title{
Using Paraffin PCM to Make Optical Communication Type of Payloads Thermally Self-Sufficient for Operation in Orion Crew Module
}

\author{
Michael K. Choi* \\ NASA Goddard Space Flight Center, Greenbelt, MD 20771
}

\begin{abstract}
An innovative concept of using paraffin phase change material with a melting point of $\mathbf{2 8}^{\circ} \mathrm{C}$ to make Optical Communication type of payload thermally self-sufficient for operation in the Orion Crew Module is presented. It stores the waste heat of the payload and permits it to operate for about one hour by maintaining its temperature within the maximum operating limit. It overcomes the problem of relying on the availability of cold plate heat sink in the Orion Crew Module.
\end{abstract}

\section{Nomenclature}

C $\quad=$ carbon

$H \quad=$ hydrogen

$N \quad=$ carbon number

$P C M=$ phase change material

$\rho \quad=$ density

$T \quad=$ temperature

\section{Introduction}

The Orion Multi-Purpose Crew Vehicle is a National Aeronautics and Space Administration (NASA) spacecraft intended to carry a crew of four astronauts to destinations at or beyond low Earth orbit. Lunar or Mars orbit is an example. Fig. 1 and Fig. 2 show the spacecraft. Fig. 3 shows the crew module.

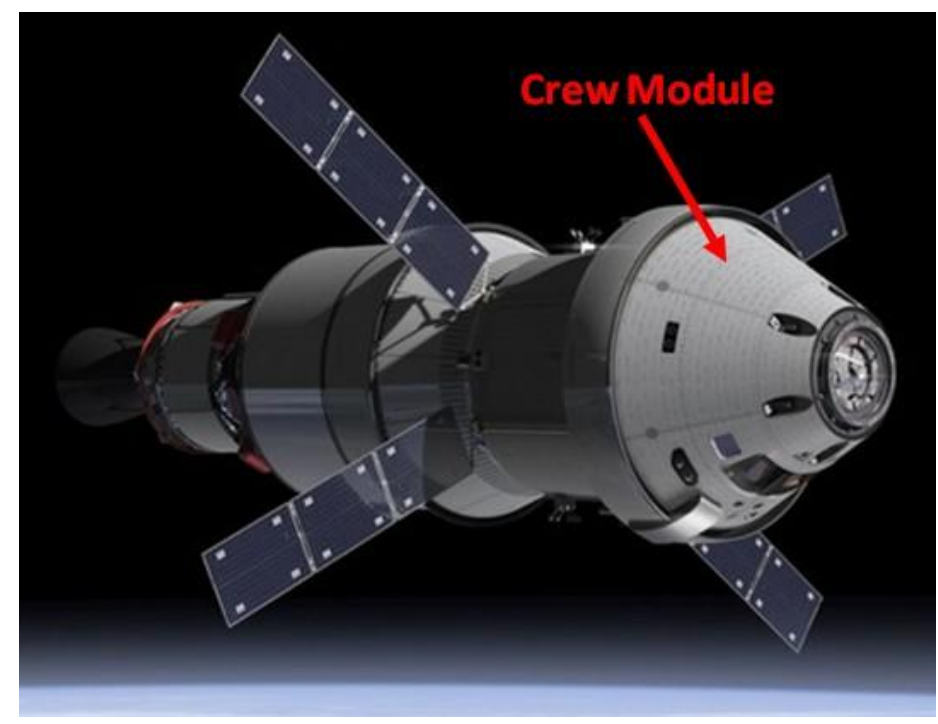

Figure 1. Orion Spacecraft.

\footnotetext{
${ }^{*}$ Senior Thermal Engineer, Thermal Engineering Branch/Code 545, AIAA Associate Fellow.
} 


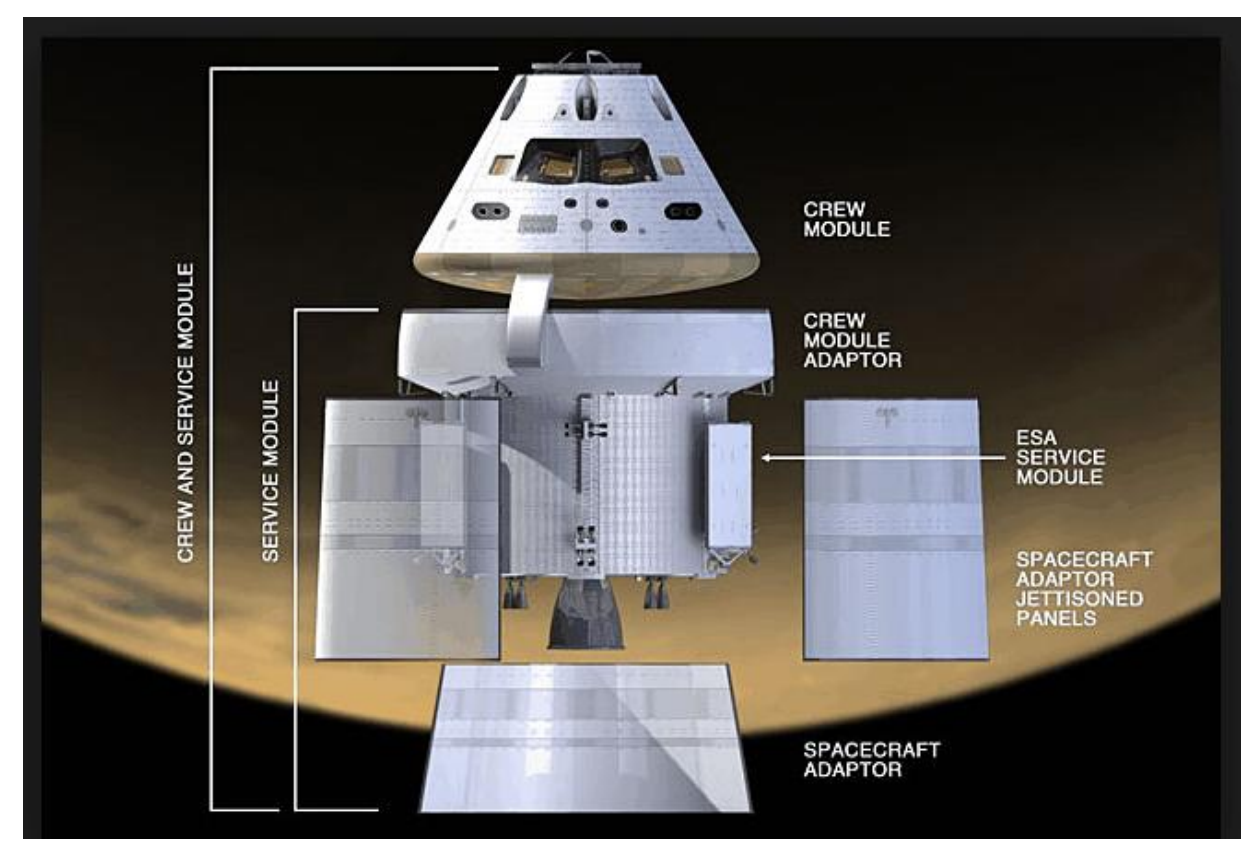

Figure 2. Orion Spacecraft.

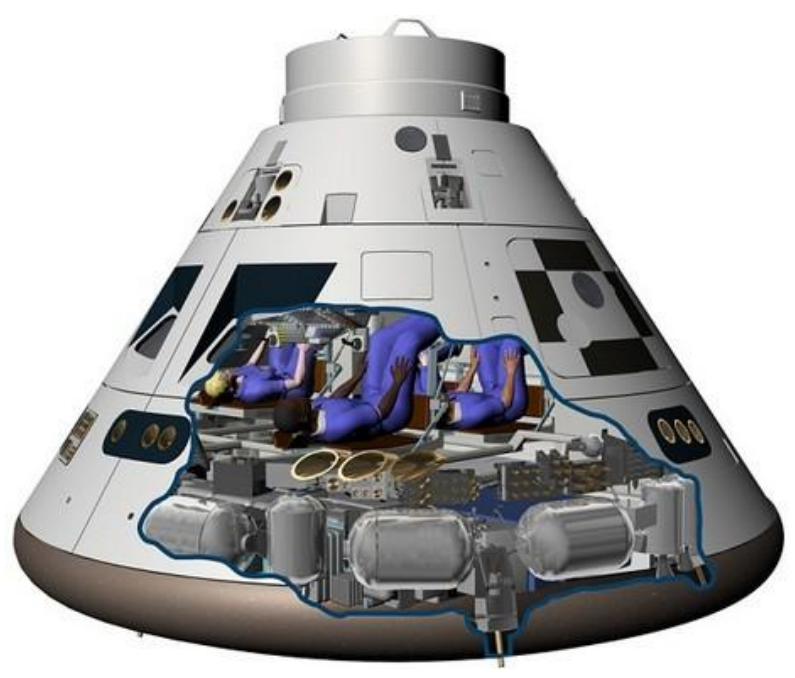

Figure 3. Orion Crew Module.

The Orion Crew Module has a pressurized cabin of approximately $20 \mathrm{~m}^{3}$ in volume. There are a number of cold plates within the Crew Module for thermal management. An Optical Communication type of payload consists of electronics boxes and modem that dissipate a significant amount of heat during science operation. Generally such type of payload operates for a short-term (e.g., approximately one hour). If these heat dissipating components are flown inside the Crew Module, they require heat rejection by conduction to the cold plates in the Crew Module. The waste heat is transported from the cold plates to the thermal radiators located outside the Service Module of the Orion spacecraft through interface heat exchangers. ${ }^{1}$ This makes such a payload thermally dependent on the Crew Module cold plates. 


\section{Paraffin PCM to Make Payloads Thermally Self-Sufficient}

If an Orion Crew Module cold plate is unavailable for temperature control of the heat dissipating components of an Optical Communication type of payload, a thermally self-sufficient option is to use paraffin phase change material (PCM) to store waste heat from payload operation. Fig. 4 and Fig. 5 show the melting point and enthalpy of fusion as a function of the $n$-alkane carbon number respectively. ${ }^{2-8}$ Generally the maximum operating temperature limit for electronics boxes and modem is $30^{\circ} \mathrm{C}$ to $40^{\circ} \mathrm{C}$. Octadecane $\left(\mathrm{C}_{18} \mathrm{H}_{38}\right)$, which has a carbon number of 18 , is selected to a) meet the component maximum operating temperature limit, b) be above the pressurized cabin ambient temperature, and c) to maximize the enthalpy of fusion. Octadecane has a melting point of $28^{\circ} \mathrm{C}$ and an enthalpy of fusion of $237 \mathrm{~kJ} / \mathrm{kg}$. The heat dissipating components can be attached to paraffin PCM panels that contain Octadecane. It requires a thermal interface ambient environment of colder than $28^{\circ} \mathrm{C}$ to prevent the paraffin from melting prior to payload operation. Typically the pressurized cabin air is maintained at $26.7^{\circ} \mathrm{C}$ for human comfort ${ }^{9}$ and is adequate to meet the requirement.

During science operation, waste heat from the payload melts the paraffin at a constant temperature of $28^{\circ} \mathrm{C}$. Fig. 6 presents the paraffin solid-liquid phase front in the paraffin panel.

The Crew Module main cabin air is actively circulated by fans, but the air behind the various closeout panels and under the crew stowage is stagnant. The heat convection coefficient is dependent on the location of the payload. Nevertheless, when the payload components are powered off for an extended period of time, the paraffin PCM freezes at a constant temperature of $28^{\circ} \mathrm{C}$ because the components lose heat to the pressurized cabin, mainly by convection. Fig. 7 presents the paraffin melt and freeze cycle.

The $28^{\circ} \mathrm{C}$ melting point of Octadecane allows these components operate within the maximum temperature limit. For example, to store $100 \mathrm{~W}$ of payload waste heat for one hour requires approximately $1.5 \mathrm{~kg}$ of Octadecane and $0.75 \mathrm{~kg}$ of aluminum shell. In calculating the volume of Octadecane required, the liquid density of Octadecane is used because it is less than the solid density. Fig. 8 shows the liquid density as a function of temperature. ${ }^{10}$ The data measured by Anton Paar Densimeter ${ }^{11}$ is indicated as AP. If $60^{\circ} \mathrm{C}$ is the fill temperature, the volume of $1.5 \mathrm{~kg}$ Octadecane required, plus a $30 \%$ margin, is calculated to be $2,540 \mathrm{~cm}^{3}$ based on its liquid density of $0.768 \mathrm{~g} \mathrm{~cm}^{-3}$ at $60^{\circ} \mathrm{C}$. The thermal conductivity of paraffin is low $\left(0.21-0.24 \mathrm{Wm}^{-1} \mathrm{~K}^{-1}\right)$. Therefore the thickness of paraffin panels is limited. Assuming the thickness of Octadecane is $1 \mathrm{~cm}$, the area is $2,540 \mathrm{~cm}^{2}$. Multiple paraffin panels, such as two $35.6 \mathrm{~cm} \times 35.6 \mathrm{~cm} \times 1 \mathrm{~cm}$ panels, can be used to add up to this area and to fit the footprint of the heat dissipating components. The mass and volume can be scaled linearly for other power dissipation or science operation time.

The aluminum shell is fine pore aluminum honeycomb core embedded with K1100 carbon fibers, aluminum 6061-T6 frame, and aluminum 1100-H19 facesheets. The carbon fibers are used to enhance thermal conduction through the panels. A thermal interface material is required to maximize heat conduction from the heat dissipating components to the paraffin panels. Examples are indium foil and T-pli.

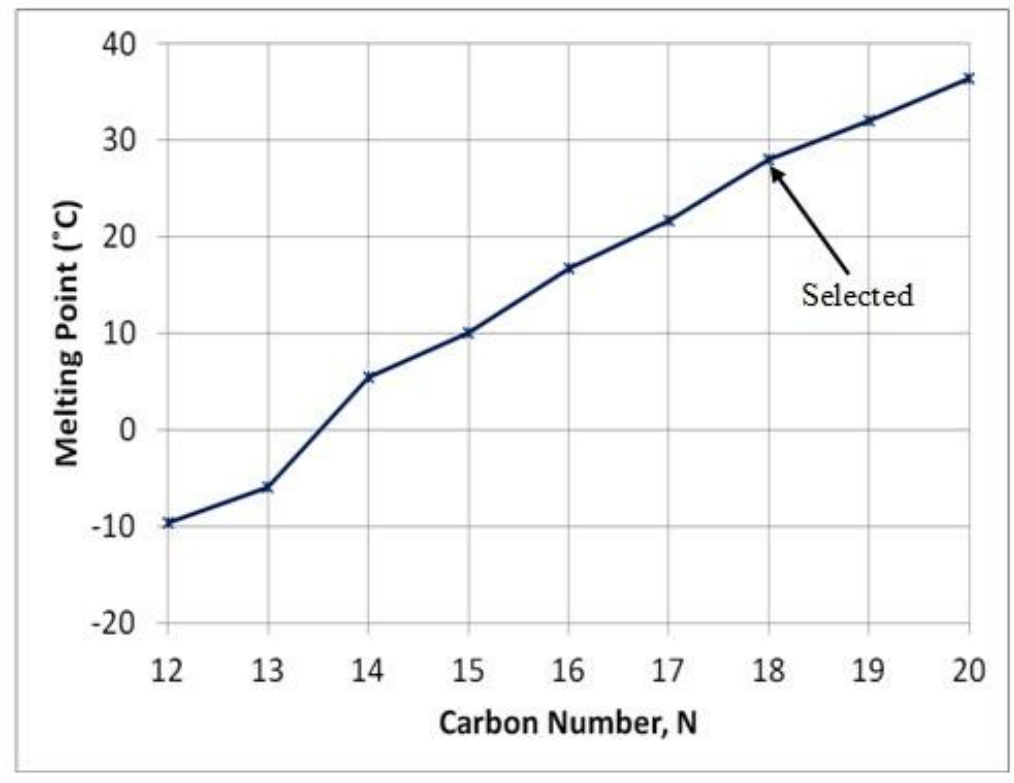

Figure 4. Melting Point of n-Alkanes $\left(\mathrm{C}_{\mathrm{N}} \mathrm{H}_{2 \mathrm{~N}+2}\right)$. 


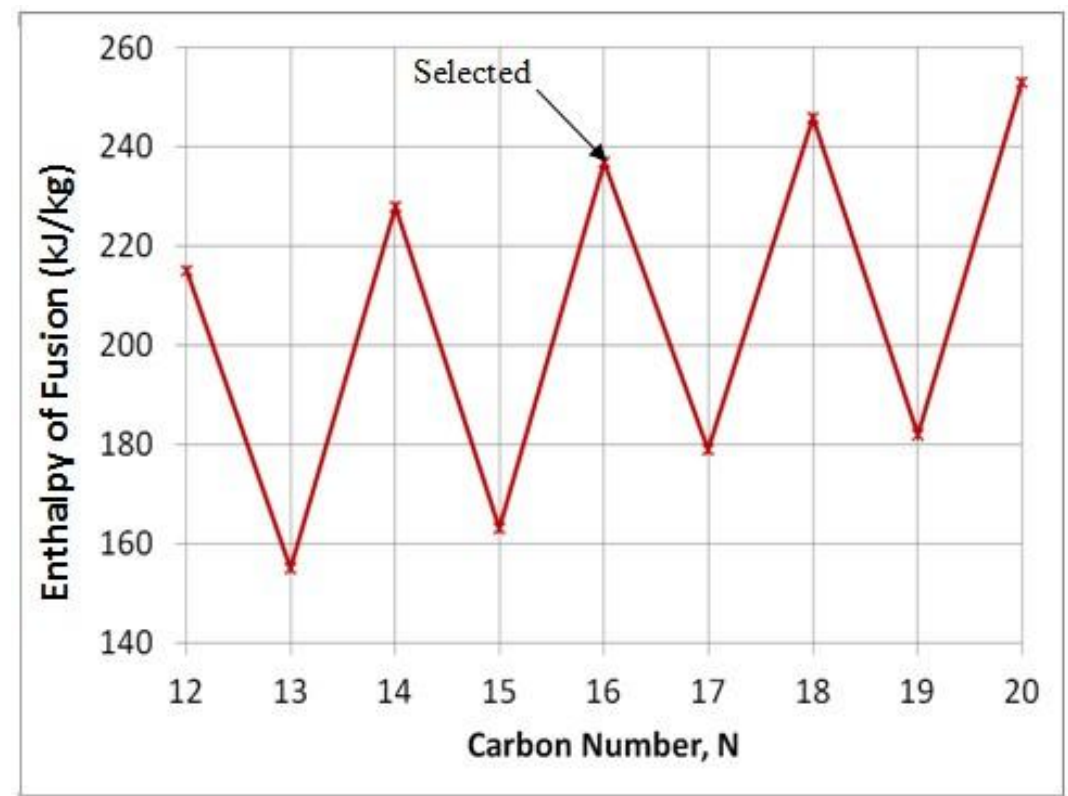

Figure 5. Enthalpy of Fusion of n-Alkanes $\left(\mathrm{C}_{\mathrm{N}} \mathrm{H}_{2 \mathrm{~N}+2}\right)$.

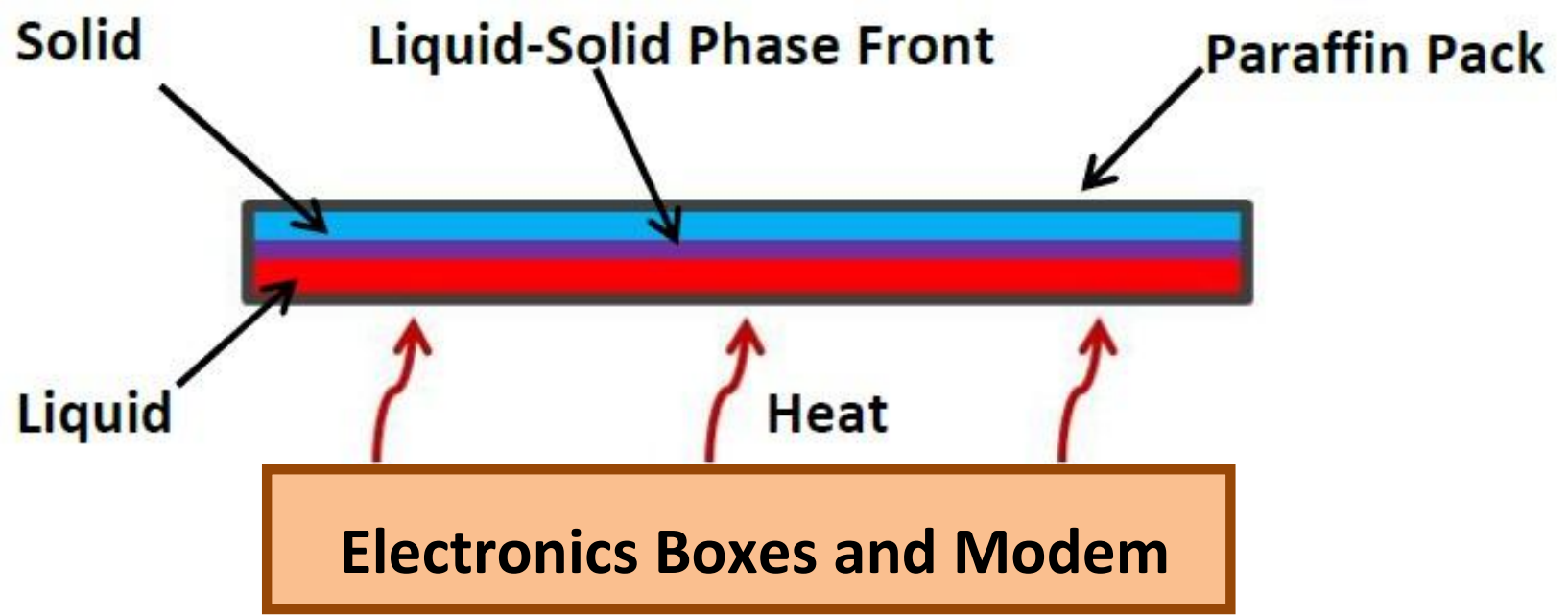

Figure 6. Solid-Liquid Phase Front in Paraffin Panel. 


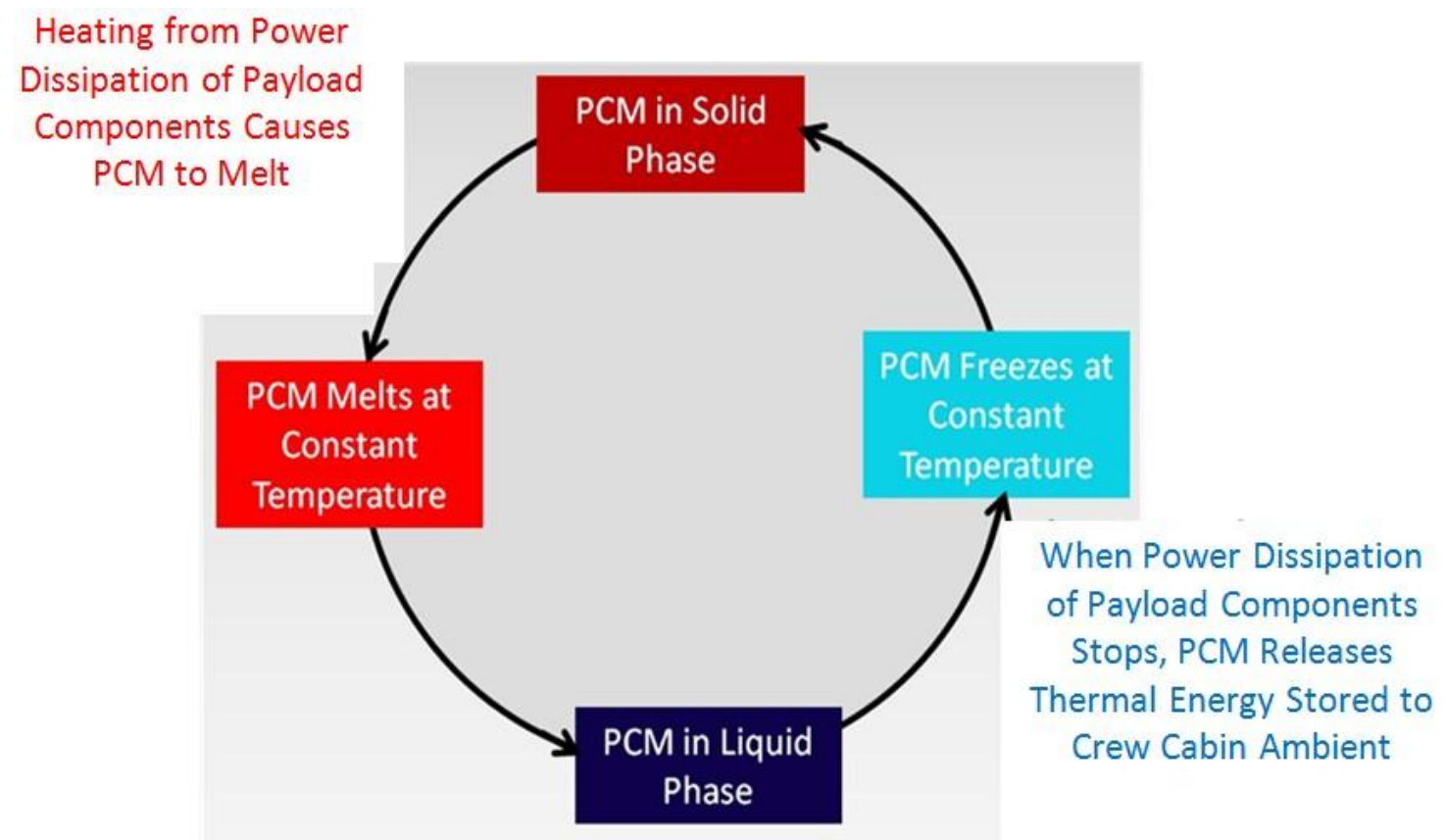

Figure 7. Paraffin Melt and Freeze Cycle.

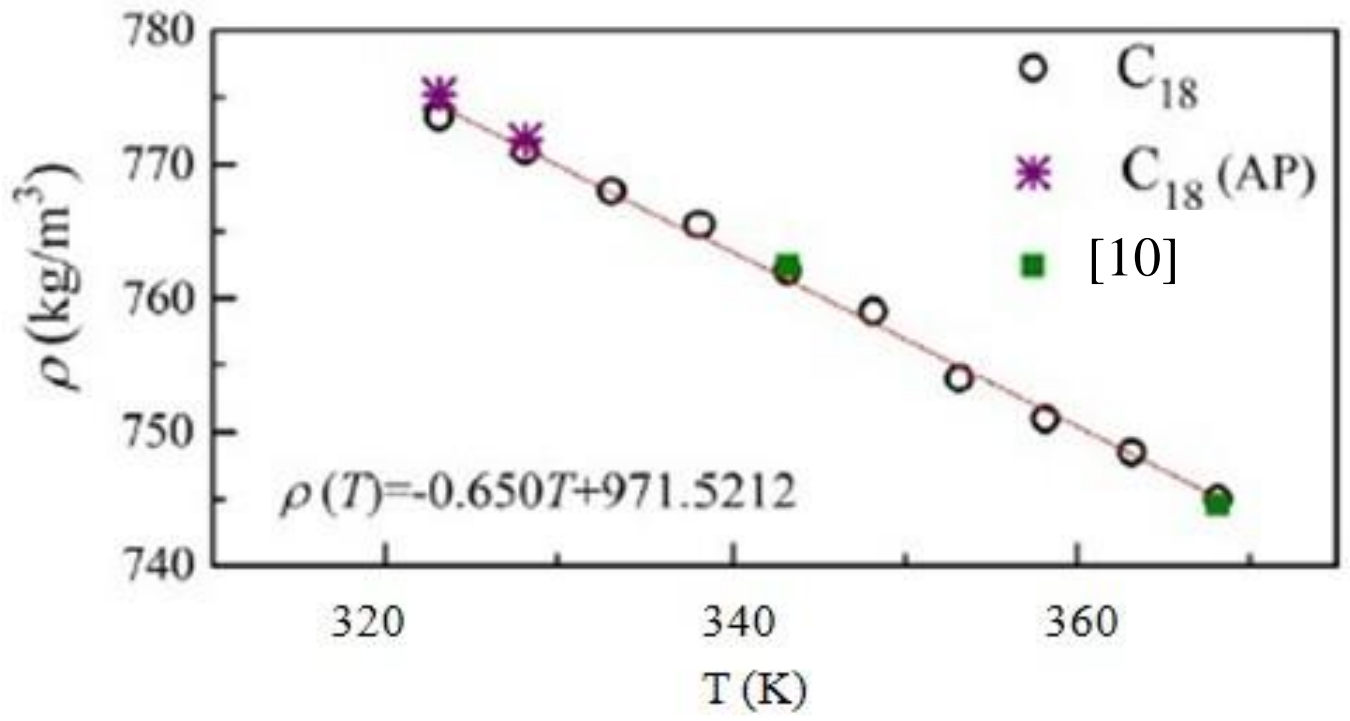

Figure 8. Density of Octadecane (with $\mathrm{C}_{18}$ ) As a Function of Temperature in Liquid Phase.'

\section{Paraffin PCM Flight Heritage}

Two small paraffin packs (Fig. 9) are flown on the NASA MESSENGER Mercury Dual Imaging System (MDIS) instrument. ${ }^{2}$ The paraffin is dodecane $\left(\mathrm{C}_{12} \mathrm{H}_{26}\right)$. Paraffin panels (Fig. 10) were built for the GSFC VCL project. $^{2}$ There was no degradation after 5,000 thermal vacuum cycles. The technology readiness level (TRL) of paraffin phase change material is at least 7. 


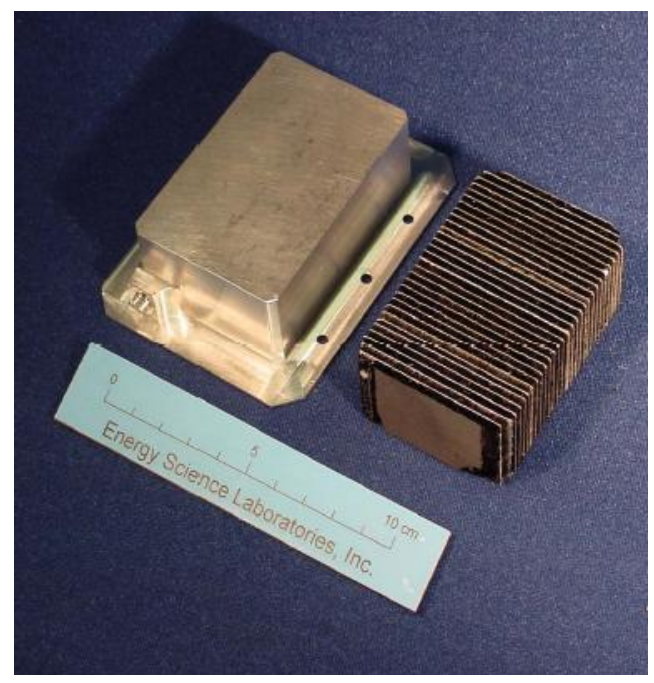

Figure 9. Paraffin Pack Flown on MESSENGER MDIS $(\sim 7 \mathrm{~cm} \mathrm{x} \sim 5 \mathrm{~cm}$ Footprint $){ }^{2}$

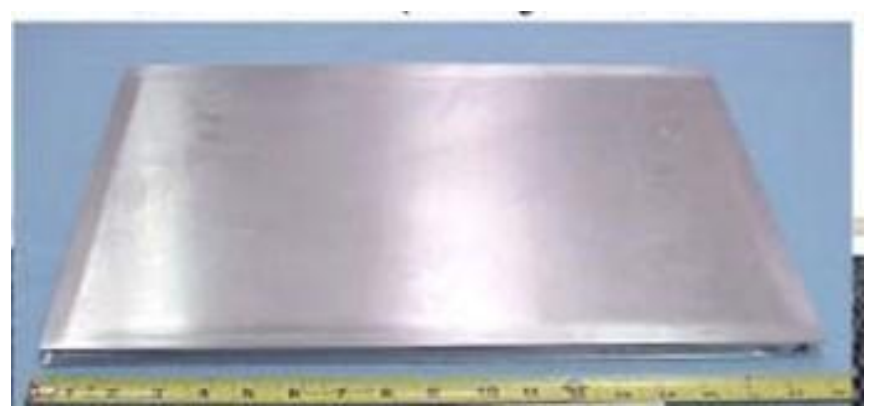

Figure 10. Paraffin Panel $(25.4 \mathrm{~cm} \times 25.4 \mathrm{~cm} \times 1 \mathrm{~cm})$ for NASA VCL Project. ${ }^{2}$

\section{Conclusion}

This paper presents an innovative thermal design concept of using paraffin $\mathrm{PCM}$ with a $28^{\circ} \mathrm{C}$ melting point to store waste heat from science operation of an Optical Communication type of payload while in the Orion Crew Module. It permits such a payload to operate for up to about one hour by maintaining its temperature within the $30^{\circ} \mathrm{C}$ to $40^{\circ} \mathrm{C}$ maximum operating limit. It makes such a payload thermally self-sufficient for operation in the Orion Crew Module. It overcomes the problem of dependence on the availability of cold plate heat sink in the Orion Crew Module.

\section{References}

Wang, X. and Yuko, J., "Thermal Performance of Orion Active Thermal Control System With Seven-Panel ReducedCurvature Radiator", NASA/TM—2010-216893, NASA GRC, Oct. 2010.

2 Knowles, T. R., "PCM Thermal Control of Nickel-Hydrogen Batteries", PL-TR--93-1075, Phillips Laboratory, Kirtland Air Force Base, NM, June 1993.

3 Knowles, T. R., "Phase Change Composite Thermal Energy Storage", Energy Science Laboratories, Inc., San Diego, CA, Sept. 2007.

Kedl, R. J., "Wallboard with Latent Heat Storage for Passive Solar Applications", ORNLTM-11541, Oak Ridge National Laboratory, Oak Ridge, TN, May 1991.

${ }^{5}$ Lewis, R.J., Sr (Ed.), Hawley's Condensed Chemical Dictionary, $12^{\text {th }}$ ed., New York, NY: Van Nostrand Rheinhold Co., p. 596, 1993.

${ }^{6}$ Hale, D.V., et al., Phase Change Materials Handbook, NASA-CR-61363, 1971.

${ }^{7}$ Humphries, W.R., and Griggs, E.I., A Design Handbook for Phase Change Thermal Control and Energy Storage Devices, NASA-TP-1074, 1977. 
Poling, P. E., et al., Perry's Chemical Engineers' Handbook $8^{\text {th }}$ ed., McGraw-Hill, New York, 2008.

${ }^{9}$ Miller, S. and Alvarez-Hernandez, A., "Effects of Re-entry and Post-Landing Heating on the Orion Crew Module Cabin Air Temperature", TFAWS-08-1019, Thermal \& Fluids Analysis Workshop, Aug. 18 -22, 2008. San Jose, CA.

${ }^{10}$ Velez, C., et al., "Temperature-dependent thermal properties of solid/liquid phase change even-numbered n-alkanes: nHexadecane, n-octadecane and n-eicosane", Applied Energy 143 (2015), pp. 383-394.

${ }^{11}$ Dadgostar, N. and Shaw, J., "A predictive correlation for the constant-pressure specific heat capacity of pure and ill-defined liquid hydrocarbons", Fluid Phase Equilibria, Vol. 313, 15 January 2012, pp. 211-226. 